\title{
Population exposure to ultrafine particles: size-resolved and real-time models for highways
}

\author{
Shanjiang Zhu' ${ }^{1}$, Julian D. Marshall ${ }^{2}$, David Levinson ${ }^{3,4}$
}

1. Assistant Professor, George Mason University, Department of Civil, Environmental, and Infrastructure Engineering, 4400 University Drive, Fairfax, Virginia, 22030, szhu3@gmu.edu

2. Professor, University of Washington, Department of Civil and Environmental Engineering, jdmarsh@uw.edu

3. Professor, University of Minnesota, Department of Civil, Environmental, and GeoEngineering, dlevinson@umn.edu

4. Professor, University of Sydney, School of Civil Engineering. 
Abstract: Prior research on ultrafine particles (UFP) emphasizes that concentrations are especially high on-highway, and that time on highways contribute disproportionately to total daily exposures. This study estimates individual and population exposure to ultra-fine particles in the Minneapolis St. Paul (Twin Cities) metropolitan area, Minnesota. Our approach combines a real-time model of on-highway size-resolved UFP concentrations (32 bins, 5.5 to $600 \mathrm{~nm}$ ); individual travel patterns, derived from GPS travel trajectories collected in 144 individual vehicles (123 hours at locations with UFP estimates among 624 vehicle-hours of travel); and, loop-detector data, indicating realtime traffic conditions throughout the study area. The results provide size-resolved spatial and temporal patterns of exposure to UFP among freeway users. On-highway exposures demonstrate significant variability among users, with highest concentrations during commuting peaks and near highway interchanges. Findings from this paper could inform future epidemiological studies in onroad exposure to UFP by linking personal exposures to traffic conditions.

\section{Introduction}

Exposure to particulate matter (PM) is associated with respiratory and cardiovascular disease (e.g. Dockery (2001); Pope III et al. (2002)). Ultrafine particles (UFP; PM with diameter less than $0.1 \mu \mathrm{m}$ ) have drawn increasing research interest because, relative to other particles, UFP can be more toxic to lab animals (Donaldson et al., 1998; Warheit et al., 2006), be harder to be removed by macrophages in the lung (Jaques and Kim, 2000; Oberdorster et al., 2005), and more easily enter the circulatory system and travel to the heart, brain, and other organs (Oberdorster et al., 2004). While larger particles are often measured based on mass, UFP typically are measured in terms of the number of particles (PN). Polluted air typically has many UFP (in terms of number [typical values: $10^{4}-10^{6}$ ])

yet their total mass is small (typical total mass for UFP is less than $1 \mu \mathrm{g} \mathrm{m}^{-3}$ ) (Sioutas et al., 2005, Seinfeld, J. H., \& Pandis, S. N. 2012).

Urban traffic, especially heavy-duty diesel freight, is a major source of UFP emissions and exposures (e.g. Shi et al. (2001); Wahlina et al. (2001) Terzano et al. 2010). Harrison et al (2011) showed factors related to the emissions on one road in central London accounted for $40.5 \%$ of particle volume and $71.9 \%$ of particle number, and revealed that solid carbonaceous particles from diesel exhaust was the largest contributor to particle number (38\%) and second to particle volume (18.8\%). On-road measurements (Morawska et al., 1999; Zhu et al., 2002a, Zhu et al., 2002b) indicate that UFP concentrations are much higher on-road than the urban background, and concentrations decline rapidly away from highways. For example, for the I-405 freeway in Los Angeles, CA, Zhu et al. (2002a) report an order of magnitude drop in UPM concentrations ( 6 to $220 \mathrm{~nm}$ ) between $30 \mathrm{~m} \mathrm{(100-}$ $\left.200 \times 10^{3} \mathrm{~cm}^{-3}\right)$ and $300 \mathrm{~m}\left(30-40 \times 10^{3} \mathrm{~cm}^{-3}\right)$ from the freeway. Concentrations at $300 \mathrm{~m}$ were indistinguishable from upwind background. Results for the I-710 in Los Angeles were similar (Zhu et al., 2002b). More recently, Hagler et al. (2010) showed that median UFP 
level in near road areas $(20 \mathrm{~m}-150 \mathrm{~m})$ were a factor of 1.8-1.2 higher than urban background. Wang and Gao (2011) found PM2.5 number concentration reached the peak on street side, but the mass concentration was the highest on subway trains using data collected in the New York City. Studies have compared UFP concentrations by mode (e.g., car, subway, and bicycle) (Both et al. 2013, Boogaard et al., 2009; Kaur et al., 2005; Kingham et al., 2007; Knibbs and de Dear, 2010; Ragettli et al 2013). A comprehensive review of studies in the field of UFP is provided by Morawska et al. (2008), Knibbs et al (2011), and Kumar et al (2011).

Measurements by Kaur and Nieuwenhuijsen (2009) of UFP in London, found that exposures are correlated with average hourly bidirectional traffic flow. Wallace and Ott (2010) measure UFP exposure in two cars on 17 trips on major highways on the East and West Coasts of the United States; they concluded that in-vehicle exposures represent 17\% of the total daily exposure for a typical suburban nonsmoker. In contrast, Fruin et al. (2008), studying on-road concentrations and average driving time, conclude that $33 \%$ to $45 \%$ of total UFP exposure for Los Angeles residents occurs during traveling in vehicles, which only accounts for $6 \%$ of the time. Their results emphasize that because concentrations and number of people on-roadway vary in time and space, estimates based on average values are not accurate. Westerdahl et al. (2005) pointed out that further studies are needed to quantify the influence of traffic, route, vehicle ventilation and meteorological influences. de Nazelle et al. (2012) compared the exposure of travelers in different modes using data collected from Barcelona and showed car riders on average had the highest exposure. Both et al. (2013) conducted a similar study in Jakarta, Indonesia based on samples collected from 36 individuals and concluded the exposure for public transport riders was higher than car riders. Quiros (2013) modeled UFP exposure using data collected along a 1-km urban residential roadway, in Santa Monica, CA. Hudda et al. (2012) tried to correlate the in-vehicle ultrafine particle exposures to on-road concentrations using data collected from 43 vehicles. Xu and Zhu (2013) further investigated several ways to reduce the in cabin exposure to UFP. For health implications related to UFP exposure, Kubesch et al (2014) showed that traffic-related UFP exposure would slightly increase diastolic blood pressure based on a two-hour real world experiment with 28 participants. A similar study showed detectable impact of trafficrelated pollutants (UFP is one of them) on lung function. Many studies called for more effort to provide better estimates of on-road exposures to UFP for both individual travelers and the general public.

To bridge this gap, this study evaluates both population and individual exposure to UFP on freeways in the Minneapolis - St. Paul (Twin Cities) metropolitan area, Minnesota. Most previous studies focus either on emission models, or on individual UFP exposure at a few limited locations. None of these studies investigated the network-wide impact to the 
general public as a whole. In our work, we estimate size-resolved exposures for during 44 days in year-2008 for $100 \%$ of the highway-vehicle population and then separately for a sample of vehicles for which we have GPS-recorded travel times and locations. We employ a UFP concentration model, which was previously developed by Aggarwal et al. (2012) to associate on-road UFP concentration with traffic volume and speed. The next section briefly describes the concentration model used in this paper. The pattern estimated UFP concentration and exposure is presented and discussed. Findings from this research advance our understanding of personal exposure to UFP and may inform future UFP exposure studies.

\section{Methods}

The objective of this study is to estimate on-highway exposure to UFP for individuals and the general public. UFP are generally measured as number concentrations (e.g., number of particles per $\mathrm{cm}^{-3}$ ). Particle sizes (e.g., $\mathrm{nm}$ ) refer to aerodynamic diameter; size ranges refer to particles with diameters between the lower and upper ends of that range. The use of size ranges is necessary when talking about environmental concentrations. For example, all else being equal, one would expect more particles in a wider size range than in a narrower size range (e.g., more particles between $60 \mathrm{~nm}$ and $70 \mathrm{~nm}$ than between $60 \mathrm{~nm}$ and $61 \mathrm{~nm}$ or between 60.0 and $60.1 \mathrm{~nm}$ ). Our use of the term "exposure" refers to on-freeway air; others have investigated the relationship between concentrations on-freeway and in-vehicle (Hudda et al., 2011; Hudda et al., 2012; Hudda and Fruin, 2013; Knibbs et al., 2010; Qi et al., 2008). Reasons for considering particle size distributions - as is done here - include that different sizes may come from different sources, may interact differently in the environment and (after being inhaled) inside the body, and may have different health impacts.

Since traffic congestion usually implies both high UFP exposure per capita and high traffic flow, the combination of which suggests high exposure of the public as a whole. Therefore, this study combined historical data for traffic conditions documented by the Minnesota Department of Transportation (MnDOT) and on-road UFP concentration collected through a sample to model UFP concentration on the Twin Cities network. Exposure of freeway users to UFP can then be estimated based on the same traffic count data. This study also differentiates from previous studies by providing insights on individual en-route exposure to the UFP using individual GPS travel trajectory collected at the Twin Cities. This approach allows minute-to-minute modeling of UFP exposure as people travel within the urban freeway microenvironment, revealing spatial and temporal patterns of individual UFP exposure with high details.

The study location is the Twin Cities (Minneapolis, St Paul), Minnesota. To estimate onroad concentrations, we employ publicly available real-time traffic data and a prior model 
by Aggarwal et al. (2010) that predicts real-time size-resolved UFP concentrations on freeways. Details of the model and model-performance are available elsewhere (Aggarwal et al., 2010), and summarized following. Briefly, size-resolved UFP number concentrations ( 32 bins, $5.5 \mathrm{~nm}$ to $600 \mathrm{~nm}$ ) were measured on Minnesota freeways during the summers of 2006 and 2007 (Johnson et al., 2009), with a total of 19 sampling days. Aggarwal et al. (2010) developed two-way stratified multi-linear regressions models, associating observed UFP concentrations with real-time meteorological and traffic data. On-road concentration of UFP in different sizes can then be estimated using the estimated parameters corresponding to different bins. Model adj- $\mathrm{R}^{2}$ was 0.77 for the overall model, with strongest predictions in the $10-100 \mathrm{~nm}$ range (average adj- $\mathrm{R}^{2}=0.85$ ). Table 5 summarized parameters for models of 32 bins, and for the total number of UFP of all sizes. Figure 1 illustrates the flow chart of this study.

Application of the Aggarwal model here requires real-time traffic and meteorology information for times and locations of interest. To avoid extrapolation, we only apply the Aggarwal model to days when meteorological and traffic conditions are similar to initial field studies, for example, when the temperature falls between 17.8 to 33.9 Celsius and wind speed less than $23 \mathrm{~m} \mathrm{~s}^{-1}$. Traffic condition constraints are given in Tables 1 and 2 . We therefore restricted our study period to the 44 days during 2008 for which meteorology conditions met the temperature and wind-speed constraints for more than 18 hours $(75 \%$ of a day). We then further constrained our study to the 570 hours ( $54 \%$ of time; $45 \%$ of traffic volume) for which traffic conditions were similar to those during the original field studies. This loss of information (approximately half of the time) is a limitation of our approach. If additional field observations were available, we could extend our approach to cover a wider range of conditions. Further discussion of this limitation is below.

Figure 2 illustrates predicted total UFP PN concentration. Aggarwal found that concentration (measured in logarithm of the number of UFP) is proportional to traffic volume and inversely proportional to traffic speed. Intuitively, UFP concentrations are lower when there is less traffic, traveling at free-flow speed. Their model is applied to realtime traffic data, to estimate 1-minute average UFP concentrations on freeways. In Figure 2, different color themes represent different levels of UFP concentrations of all sizes as a function of traffic volume and speed, while the black dots illustrate the number of minutes when different traffic conditions were observed during the 44 days. Figure 2 also shows that not all traffic conditions observed during those 44 days are within the observed range as in Aggarwal's model, where the color theme is removed. Among them, some traffic conditions are rare (e.g. extremely low speed and volume) on freeways in the Twin Cities; others may be unstable and rare (e.g. low speed and high volume). The coverage is also limited by the duration of observations in Aggarwal et al. (2010). For precaution, we will limit our discussions on traffic conditions within the range where sufficient data are 
available, while trying to extrapolate to cover all conditions in a subsequent sensitivity analysis. Lastly, Figure 2 only illustrates the estimated number of all UFP ranging from 5.5 $\mathrm{nm}$ to $600 \mathrm{~nm}$. A similar graph can also be drawn for the 32 bins corresponding to different size ranges. Using these models and traffic data observed from detectors deployed along major freeways in the Twin Cities, the following section will analyze the UFP concentration and exposure under different conditions.

\section{Results}

\section{Detector Data}

Loop detectors have been widely deployed to constantly monitor the traffic conditions on the freeway system in the Twin Cities. Figure 3 illustrates the freeway network and the location of loop detector stations.

Previous research (Aggarwal et al., 2010; Sioutas et al., 2005) shows that traffic from both directions have contributed to the concentration of UFP because of their physical vicinity to one another. Therefore, detectors from both directions are paired together to provide volume and speed of traffic passing through a location. The distance of stations in opposite directions (e.g. Northbound and Southbound) varies; a threshold of $200 \mathrm{~m}$ has been chosen in this study because previous studies show that the impact of automobiles on the UFP concentration declines rapidly beyond that distance (Zhu et al., 2002a, Zhu et al., 2002b). In total, 454 bidirectional pairs of loop detectors are identified, with a mean (standard deviation) separation distance of 48 (24) $\mathrm{m}$.

The traffic flow and speed data have been collected for all detector stations and for each one minute interval in 2008. The flow and speed of paired detectors are then aggregated and applied to all 33 models (of 32 bins of different particle sizes and of the total number of all sizes). The concentration of UFP on the entire freeway system can be estimated by further assuming that flow and speed measured at the detector stations are constant on the approximately $1 \mathrm{~km}$ freeway segment they represent.

\section{Exposure Concentrations}

As previously indicated, only 44 days in the year 2008 have a valid time period longer than $18 \mathrm{~h}$ (75\% of a day) due to constraints of meteorological conditions. We will present next the on-road concentrations, and then the exposures. This study only considers those days and the UFP concentration is predicted, given the volume and speed data at each station at an interval of one minute. The number of particles is then averaged across the 44 days. Figure 4 summarizes the general pattern of PN concentration of all UFP ranging from 5.6 $\mathrm{nm}$ to $523.3 \mathrm{~nm}$ across a day by presenting the mean, and the 10th, 25th, 75th, and 90th percentile PN concentrations among all 454 stations for each hour (total: 44 days), for both weekday and weekend, respectively. The variance in PN concentration level among all 
loop-detector stations is small during the off-peak period. During the peak period the variance is larger, reflecting diverse traffic conditions due to difference in station locations and in corresponding travel demands.

Concentration patterns in Figure 4 differ for weekdays and weekends, reflecting differences in travel patterns: two concentration-peaks during weekdays, a single, broad concentration-peak during weekends. Note the right-sided skew in the data: in Figure 4, the mean is close to $75^{\text {th }}$ percentile most of the time.

Traffic flow data from loop-detector stations indicate how many people drive through different locations in the Twin Cities freeway network in each minute. Given the UFP PN concentration estimated by our models, personal exposure to UFP can be estimated. Figure 5 summarizes the temporal pattern of personal exposure to UFP in the Twin Cities network, while Figure 6 presents the average daily cumulative UFP exposure at different locations.

Although the temporal pattern of UFP exposure is similar to that of PN concentration, the difference in magnitude between peak period and off-peak period exposures is further enhanced by the different travel demand levels during different periods. While peak hour concentration is only about 10 times larger than the off-peak hour concentration, the peak hour exposure expands about 100 times compared to its off-peak hour counterpart.

Interestingly, although perhaps not surprisingly, all places with extreme high exposure levels are close to major freeway interchanges compared to places with relatively lower exposure. For example, cumulative daily exposure to UFP averaged across all 44 days reaches peaks along I-394 when it meets I-94, TH 100, TH 169, and I-494. Similar trends can also be found along I-494 and I-694. In addition to there simply being more vehicles and thus more emissions because two freeways are occupying nearby $\mathrm{x}-\mathrm{y}$ coordinates, traffic usually travels slower near interchanges due to frequent lane-changes owing to merging and exiting, which may help to explain higher concentration and exposure levels. The highest daily cumulative exposure to UFP is observed on I-94 near downtown Minneapolis, where I-94 joins I-394 and I-35W. Exposure during weekends exhibits a flatter pattern, with only a few hot spots near major interchanges.

Since exposure to UFP is a function of travel demand (measured by the number of vehicles passing a freeway location) and particle concentration (which is also linearly correlated with travel demand), it is expected that UFP exposure and concentration will be highly correlated. Figure 7a presents the correlation between daily total UFP exposure at one location and the corresponding person-weighted UFP concentration (defined by equation 1), while Figure $7 \mathrm{~b}$ shows the correlation between daily total exposure and simple mathematical average (defined by equation 2) of concentration at one location. Here $c_{n}$ and $\mathrm{V}_{\mathrm{n}}$ represent estimated PN concentration and observed traffic volume during time one- 
minute period n, respectively. Each of the 19,976 points in Figures $7 \mathrm{a}$ and $7 \mathrm{~b}$ represents the observation for one detector-day.

As revealed by the high $\mathrm{R}^{2}$ value, a simple polynomial function can well capture the central trend between daily exposure and average UFP concentration at one location. However, both Figures $7 \mathrm{a}$ and $7 \mathrm{~b}$ exhibit strong heteroscedasticity: as the concentration becomes larger, the distribution of estimated daily exposure to UFP scatters to a wider range. Different traffic conditions (speed and traffic flow in our models) can generate the same PN concentration. However, exposure to UFP may differ depending on the number of vehicles passing through.

More importantly, large temporal and spatial variances in personal exposure to UFP are expected according to Figures 5 and 7. People who travel a lot and frequently visit those freeway segments with high UFP concentration will experience a much higher exposure to UFP. This potentially large disparity in personal PN exposure may raise concerns for epidemiological studies if those studies estimate exposures at home locations only. We illustrate this problem using individual GPS data in the following section.

\section{Particle Size}

Particle size is influenced in part by the formation mechanism, and likely impacts the toxicity of particulate matter. Figure 8 illustrates the person-weighted average exposure to particles in different size ranges. Exposure to particles in the range of 8.06-9.13 nm is highest during weekdays. PN exposure decreases as particle size becomes either smaller or larger. It reaches the lowest level in the range of 254.8-294.3 nm and moves upwards again as particle size increases. During different time of the day, PN exposure exhibits similar patterns across different particle sizes. However, the temporal patterns differ for weekdays and weekends. We see highest PN exposure during weekday morning and afternoon peak periods (8:00 am and 5:00 pm), while exposure at 8:00 am during weekends is the lowest of the four time periods showed in Figure 8. In contrast, the exposure is the highest in the afternoon (from 12:00pm to 5:00pm) during weekends.

\section{Individual exposures}

This section employs GPS data collected in the Twin Cities for a travel behavior study to evaluate individual exposure to UFP on the Twin Cities freeways. The GPS data that was used (a subset of all data collected) was based on 144 instrumented vehicles which recorded their travel trajectory from August 25 to September 30, 2008 at one second intervals or every 25 meters, depending on the type of GPS devices used (two types of GPS devices have been used). More details about the GPS-based study are provided by Zhu et al. (2010). The satellite time recorded by GPS allows us to match presence of study 
participants with estimated UFP concentration on the Twin Cities freeways and estimate individual exposure to UFP. Comparing previous analysis based on aggregate travel demand monitored by loop-detector stations, GPS-based analysis can better reveal diversity in driving pattern and the resulting difference in exposure level. We can further associate this difference with drivers' social-demographic information. Therefore, the methodology developed in this research will inform future epidemiological studies.

In the study period, the GPS collectively recorded $136,781 \mathrm{~km}$, or 2,371 passenger hours of travel. The average speed is about $56 \mathrm{~km} / \mathrm{h}$. On freeways, the GPS recorded 62,606 km, or 805 passenger hours of traveling, with an average speed of about $77 \mathrm{~km} / \mathrm{h}$. Constrained by data availability, we will only evaluate exposure on freeways in this study. Future research should model arterials and city streets. Seven days during the GPS-based study matched the constraints set by meteorological conditions. Therefore, 5,570 one-minute intervals $(8.1 \%)$ out of a total 1,140 freeway vehicle hours are analyzed.

GPS points on the freeway system are selected by comparing their positions with the Metropolitan Council planning network, which has been conflated to the geometry of real roads and is fairly accurate. By comparing the time and position information of GPS points with the UFP concentration map, individual exposure to the UFP on-freeway system is estimated. Figure 9 summarizes exposure to UFP during each one-minute interval on freeways by all subjects, sorting from small to large.

Exposure per traveler to UFP on-freeway during most one-minute intervals ranges from 100,000 to $5,000,000$, measured in particle number. However, some travelers experienced an exposure level as high as $11,910,000$. As a comparison, the highest reading of total number of particles during the initial field study is about $16,270,000$ during one-minute interval. Therefore, some people will experience very high exposure to UFP, which is about three orders of magnitude higher than city background level, while driving on freeways. The normal probability plot in Figure 9 also suggests that for the majority of cases (Z score from -2 to 2), individual exposure to UFP (measured by particles per minute) on freeways follows a log-normal distribution.

\section{Conclusion}

This study investigates exposure to ultra-fine particle by combining an on-road UFP concentration model, traffic data, and travel patterns derived from different traffic monitoring data sources. Spatio-temporal patterns of both UFP concentrations and exposure are revealed. The time-of-day pattern of exposure to UFP presents two obvious peaks during weekdays and a flat curve during weekends. However, the difference in magnitude between the peak and off-peak periods is much larger for exposure compared to that for concentration because the presence of heavy traffic is also the source of high UFP 
concentration. A few hot spots represent a majority of total exposure to UFP since the data are highly skewed and the mean is close to the 75th percentile.

People experience highest exposure to UFP during morning and afternoon peak on weekdays, while are exposed the least on weekend mornings. The patterns are consistent with different particle sizes, but the magnitude of difference in exposure during different time of the day varies.

Spatial analysis finds that places with the highest exposure levels are close to major freeway interchanges compared to places with relatively lower exposure. This fact may be related to the higher traffic flows and slower travel speeds near interchanges, due to frequent lane-changes due to merging and exiting. Further analysis indicates that the distribution of estimated daily exposure to UFP scatters to a wider range as the concentration becomes larger. Temporal and spatial variances are expected because of the heterogeneity of individual travel patterns. People who travel a lot and frequently visit those freeway segments with high UFP concentration levels should expect higher exposure.

This study further estimates individual exposure to UFP by combining individual travel trajectory with on-road UFP concentration model. This observation confirms the significant disparity in individual exposure to UFP among population. In general, individual exposure to UFP follows a log-normal distribution. Although our exposure measure differs from the number of particles people inhale, it still raises concerns about potential adverse health effects to frequent freeway users. Findings from this paper could inform future epidemiological studies in on-road exposure to UFP.

\section{References}

Aggarwal, S., R. Jain, and J. Marshall (2010). Real time prediction of size resolved ultrafine PM on freeways. Environmental Science \& Technology 46, 2234-2241.

Both, A. F., D. Westerdahl, S.A. Fruin, B. Haryanto, and J.D. Marshall (2013). Exposure to carbon monoxide, fine particle mass, and ultrafine particle number in Jakarta, Indonesia: Effect of commute mode. Science of the Total Environment 443, 965-972.

Boogaard, H., F. Borgman, J. Kamminga, and G. Hoek (2009). Exposure to ultrafine and fine particles and noise during cycling and driving in 11 Dutch cities. Atmospheric Environment 43 (27), 4234-4242.

Dockery, D. (2001). Epidemiologic evidence of cardiovascular effects of particulate air pollution. Environmental Health Perspectives 109 (Suppl 4), 483-486.

Donaldson, K., X. Li, and W. MacNee (1998). Ultrafine (nanometre) particle mediated lung injury. Journal of Aerosol Science 29 (5-6), 553-560. 
Fruin, S., D. Westerdahl, T. Sax, C. Sioutas, and P. Fine (2008). Measurements and predictors of on-road ultrafine particle concentrations and associated pollutants in Los Angeles. Atmospheric Environment 42 (2), 207-219.

Hagler, G. S., E.D. Thoma, and R.W. Baldauf, R. W. (2010). High-resolution mobile monitoring of carbon monoxide and ultrafine particle concentrations in a near-road environment. Journal of the Air \& Waste Management Association 60(3), 328-336.

Harrison, R. M., D.C. Beddows, and M. Dall'Osto, M. (2011). PMF analysis of wide-range particle size spectra collected on a major highway. Environmental Science \& Technology 45(13), 5522-5528.

Hudda, N., S.P. Eckel, L.D. Knibbs, C. Sioutas, R.J. Delfino, and S.A. Fruin (2012). Linking invehicle ultrafine particle exposures to on-road concentrations. Atmospheric Environment 59, 578-586.

Hudda, N., and S.A. Fruin, (2013). Models for predicting the ratio of particulate pollutant concentrations inside vehicles to roadways. Environmental Science \& Technology 47(19), 11048-11055.

Hudda N., E. Kostenidou, C. Sioutas R.J. Delfino, S.A. Fruin, (2011). Vehicle and driving characteristics that influence in-cabin particle number concentrations. Environmental Science \& Technology 45(20), 8691-8697.

Jaques, P. and C. Kim (2000). Measurement of total lung deposition of inhaled ultrafine particles in healthy men and women. Inhalation Toxicology 12 (8), 715-731.

Knibbs, L.D., R.J. de Dear, L. Morawska (2010). Effect of cabin ventilation rate on ultrafine particle exposure inside automobiles. Environmental Science \& Technology 44(9), 35463551.

Johnson, J., D. Kittelson, and W. Watts (2009). The effect of federal fuel sulfur regulations on in-use fleets: On-road heavy-duty source apportionment. Environmental Science \& Technology 43 (14), 5358-5364.

Kaur, S. and M. Nieuwenhuijsen (2009). Determinants of personal exposure to PM2. 5, Ultrafine Particle Counts, and CO in a transport microenvironment. Environmental Science \& Technology 43 (13), 4737-4743.

Kaur, S., M. Nieuwenhuijsen, and R. Colvile (2005). Personal exposure of street canyon intersection users to PM2. 5, ultrafine particle counts and carbon monoxide in Central London, UK. Atmospheric Environment 39 (20), 3629-3641. 
Kingham, S., J. Pearce, and P. Zawar-Reza (2007). Driven to injustice? Environmental justice and vehicle pollution in Christchurch, New Zealand. Transportation Research Part D:

Transport and Environment 12 (4), 254-263.

Knibbs, L. and R. de Dear (2010). Exposure to ultrafine particles and PM2. 5 in four Sydney transport modes. Atmospheric Environment 44(26) 3224-3227

Knibbs, L. D., Cole-Hunter, T., and Morawska, L. (2011). A review of commuter exposure to ultrafine particles and its health effects. Atmospheric Environment 45(16), 2611-2622.

Kubesch, N., A. de Nazelle, D. Martinez, S. Guerra, S., and M. Nieuwenhuijsen, M. (2013). Lung function and-inflammation after short term exposures to traffic related air pollution and physical activity. European Respiratory Journal 42(Suppl 57), P3620.

Kubesch, N., A. de Nazelle, S. Guerra, D. Westerdahl, D. Martinez, L. Bouso, and M.J. Nieuwenhuijsen, (2014). Arterial blood pressure responses to short-term exposure to low and high traffic-related air pollution with and without moderate physical activity. European Journal of Preventive Cardiology 2047487314555602.

Kumar, P., Ketzel, M., Vardoulakis, S., Pirjola, L., \& Britter, R. (2011). Dynamics and dispersion modelling of nanoparticles from road traffic in the urban atmospheric environment—a review. Journal of Aerosol Science 42(9), 580-603.

Morawska, L., Z. Ristovski, E. Jayaratne, D. Keogh, and X. Ling (2008). Ambient nano and ultrafine particles from motor vehicle emissions: characteristics, ambient processing and implications on human exposure. Atmospheric Environment 42 (35), 8113-8138.

Morawska, L., S. Thomas, D. Gilbert, C. Greenaway, and E. Rijnders (1999). A study of the horizontal and vertical profile of submicrometer particles in relation to a busy road. Atmospheric Environment 33 (8), 1261-1274.

de Nazelle, A., S. Fruin, D. Westerdahl, D. Martinez, A. Ripoll, N. Kubesch, and M. Nieuwenhuijsen, (2012). A travel mode comparison of commuters' exposures to air pollutants in Barcelona. Atmospheric Environment 59, 151-159.

Oberdörster, G., E. Oberdörster, and J. Oberdörster (2005). Nanotoxicology: an emerging discipline evolving from studies of ultrafine particles. Environmental Health Perspectives 113 (7), 823.

Oberdörster, G., Z. Sharp, V. Atudorei, A. Elder, R. Gelein, W. Kreyling, and C. Cox (2004). Translocation of inhaled ultrafine particles to the brain. Inhalation Toxicology 16 (6-7), 437-445. 
Pope III, C., R. Burnett, M. Thun, E. Calle, D. Krewski, K. Ito, and G. Thurston (2002). Lung cancer, cardiopulmonary mortality, and long-term exposure to fine particulate air pollution. The Journal of the American Medical Association 287 (9), 1132-1141.

Qi, C., N. Stanley, D.Y. Pui, and T.H. Kuehn (2008). Laboratory and on-road evaluations of cabin air filters using number and surface area concentration monitors. Environmental Science \& Technology 42(11), 4128-4132.

Quiros, D. C., E.S. Lee, R. Wang, and Y. Zhu, (2013). Ultrafine particle exposures while walking, cycling, and driving along an urban residential roadway. Atmospheric Environment 73, 185-194.

Ragettli, M. S., E. Corradi, C. Braun-Fahrländer, C. Schindler, A. de Nazelle, M. Jerrett, R.E. Ducret-Sticha, N. Künzlia, and H.C. Phuleria, (2013). Commuter exposure to ultrafine particles in different urban locations, transportation modes and routes. Atmospheric Environment 77, 376-384.

Seinfeld, J. H., and S.N. Pandis, S. N. (2012). Atmospheric Chemistry and Physics: from Air Pollution to cClimate cChange. John Wiley \& Sons.

Shi, J., D. Evans, A. Khan, and R. Harrison (2001). Sources and concentration of nanoparticles ( $<10 \mathrm{~nm}$ diameter) in the urban atmosphere. Atmospheric Environment 35 (7), 1193-1202.

Sioutas, C., R. Delfino, and M. Singh (2005). Exposure assessment for atmospheric ultra-fine particles (UFPs) and implications in epidemiologic research. Environmental Health Perspectives 113 (8), 947-955.

Terzano, C., F. Di Stefano, V. Conti, E. Graziani, and A. Petroianni, (2010). Air pollution ultrafine particles: toxicity beyond the lung. European Review for Medical and Pharmacological Sciences 14(10), 809-821.

Wahlina, P., F. Palmgren, and R. Van Dingenen (2001). Experimental studies of ultrafine particles in streets and the relationship to traffic. Atmospheric Environment 35, 63-69.

Wallace, L. and W. Ott (2011). Personal exposure to ultrafine particles. Journal of Exposure Science and Environmental Epidemiology 21, 20-30

Wang, X. R., \& Gao, H. O. (2011). Exposure to fine particle mass and number concentrations in urban transportation environments of New York City. Transportation Research Part D: Transport and Environment 16(5), 384-391. 
Warheit, D., T. Webb, C. Sayes, V. Colvin, and K. Reed (2006). Pulmonary instillation studies with nanoscale $\mathrm{TiO} 2$ rods and dots in rats: toxicity is not dependent upon particle size and surface area. Toxicological Sciences 91 (1), 227-236.

Westerdahl, D., S. Fruin, T. Sax, P. Fine, and C. Sioutas (2005). Mobile platform measurements of ultrafine particles and associated pollutant concentrations on freeways and residential streets in Los Angeles. Atmospheric Environment 39 (20), 3597-3610.

$\mathrm{Xu}, \mathrm{B}$., and Y. Zhu, (2013). Investigation on lowering commuters' in-cabin exposure to ultrafine particles. Transportation Research Part D: Transport and Environment 18, 122-130.

Zhu, S., D. Levinson, and H. Liu (2010). Measuring winners and losers from the new I-35W Mississippi River Bridge. In Transportation Research Board 89th Annual Meeting Compendium of Papers DVD \#10-2298, January 2010, Washington DC.

Zhu, Y., W. Hinds, S. Kim, S. Shen, and C. Sioutas (2002a). Study of ultrafine particles near a major highway with heavy-duty diesel traffic. Atmospheric Environment 36 (27), 43234335.

Zhu, Y., W. Hinds, S. Kim, and C. Sioutas (2002b). Concentration and size distribution of ultrafine particles near a major highway. Journal of the Air \& Waste Management Association 52 (9), 1032-1042. 
Table 1: Number of one minute intervals within each volume-speed combinations for all 454 station pairs in the Twin Cities freeway network during 44 days in 2008 when meteorological conditions are consistent with initial field study for at least 18 hours per day

\begin{tabular}{|c|r|r|r|r|r|r|r|r|}
\hline \multirow{2}{*}{ Volume } & \multicolumn{8}{|c|}{ Speed km/h (miles/h) } \\
\cline { 2 - 10 } & $\begin{array}{c}<24 \\
(<15)\end{array}$ & $\begin{array}{c}24 \text { to } 64 \\
(15 \text { to } 40)\end{array}$ & $\begin{array}{c}64 \text { to } 80 \\
(40 \text { to } 50)\end{array}$ & $\begin{array}{c}80 \text { to } 87 \\
(50 \text { to } 54)\end{array}$ & $\begin{array}{c}87 \text { to } 93 \\
(54 \text { to } 58)\end{array}$ & $\begin{array}{c}93 \text { to } 100 \\
(58 \text { to } 62)\end{array}$ & $\begin{array}{c}100 \text { to } 105 \\
(62 \text { to } 65)\end{array}$ & $\begin{array}{c}>105 \\
(>65)\end{array}$ \\
\hline 0 & 1821448 & 0 & 0 & 0 & 0 & 0 & 0 & 114722 \\
\hline $0-40$ & 5204 & 166610 & 383525 & 423948 & 704838 & 1003786 & 965399 & 4418413 \\
\hline $40-50$ & 437 & 26548 & 37012 & 53812 & 100269 & 183469 & 218986 & 1219511 \\
\hline $50-60$ & 694 & 29249 & 51003 & 60529 & 104822 & 191493 & 235278 & 1245105 \\
\hline $60-70$ & 1059 & 30105 & 91420 & 48605 & 110787 & 199314 & 244193 & 1159735 \\
\hline $70-80$ & 1108 & 52772 & 67434 & 51928 & 108579 & 198743 & 243210 & 1031434 \\
\hline$>80$ & 1369 & 216649 & 497292 & 330490 & 492573 & 874219 & 999212 & 3359691 \\
\hline
\end{tabular}

*Another 4,587,409 detector*minutes during these 44 days are not valid because of meteorological conditions.

** Gray area indicates traffic conditions that have enough number of observations during field study. 
Table 2: Percentage of the number of one minute intervals within each volume-speed combinations compared to the total number of observations for all 454 station pairs in the Twin Cities freeway network during 44 days in 2008 when meteorological conditions are consistent with initial field study for at least 18 hours per day

\begin{tabular}{|c|r|r|r|r|r|r|r|r|}
\hline \multirow{2}{*}{ Volume } & \multicolumn{7}{|c|}{ Speed $\mathrm{km} / \mathrm{h}$ (miles/h) } \\
\cline { 2 - 9 } & $\begin{array}{c}<24 \\
(<15)\end{array}$ & $\begin{array}{c}24 \text { to } 64 \\
(15 \text { to } 40)\end{array}$ & $\begin{array}{c}64 \text { to } 80 \\
(40 \text { to } 50)\end{array}$ & $\begin{array}{c}80 \text { to } 87 \\
(50 \text { to } 54)\end{array}$ & $\begin{array}{c}87 \text { to } 93 \\
(54 \text { to } 58)\end{array}$ & $\begin{array}{c}93 \text { to } 100 \\
(58 \text { to } 62)\end{array}$ & $\begin{array}{c}100 \text { to } 105 \\
(62 \text { to } 65)\end{array}$ & $\begin{array}{r}>105 \\
(>65)\end{array}$ \\
\hline 0 & $6.3 \%$ & $0.0 \%$ & $0.0 \%$ & $0.0 \%$ & $0.0 \%$ & $0.0 \%$ & $0.0 \%$ & $0.4 \%$ \\
\hline $0-40$ & $0.0 \%$ & $0.6 \%$ & $1.3 \%$ & $1.5 \%$ & $2.5 \%$ & $3.5 \%$ & $3.4 \%$ & $15.4 \%$ \\
\hline $40-50$ & $0.0 \%$ & $0.1 \%$ & $0.1 \%$ & $0.2 \%$ & $0.3 \%$ & $0.6 \%$ & $0.8 \%$ & $4.2 \%$ \\
\hline $50-60$ & $0.0 \%$ & $0.1 \%$ & $0.2 \%$ & $0.2 \%$ & $0.4 \%$ & $0.7 \%$ & $0.8 \%$ & $4.3 \%$ \\
\hline $60-70$ & $0.0 \%$ & $0.1 \%$ & $0.3 \%$ & $0.2 \%$ & $0.4 \%$ & $0.7 \%$ & $0.8 \%$ & $4.0 \%$ \\
\hline $70-80$ & $0.0 \%$ & $0.2 \%$ & $0.2 \%$ & $0.2 \%$ & $0.4 \%$ & $0.7 \%$ & $0.8 \%$ & $3.6 \%$ \\
\hline$>80$ & $0.0 \%$ & $0.8 \%$ & $1.7 \%$ & $1.1 \%$ & $1.7 \%$ & $3.0 \%$ & $3.5 \%$ & $11.7 \%$ \\
\hline
\end{tabular}

*Another $15.9 \%$ detector*minutes during these 44 days are not valid because of meteorological conditions.

** Gray area indicates traffic conditions that have enough number of observations during the field study, which accounts for $54.1 \%$ of time with satisfactory meteorological conditions. 
Table 3: Number of vehicle trips within each volume-speed combinations for all 454 station pairs in the Twin Cities freeway network during 44 days in 2008 when meteorological conditions are consistent with initial field study for at least 18 hours per day

\begin{tabular}{|c|r|r|r|r|r|r|r|r|}
\hline \multirow{2}{*}{ Volume } & \multicolumn{9}{|c|}{ Speed km/h (miles/h) } \\
\cline { 2 - 10 } & $\begin{array}{c}<24 \\
(<15)\end{array}$ & $\begin{array}{c}24 \text { to } 64 \\
(15 \text { to } 40)\end{array}$ & $\begin{array}{c}64 \text { to } 80 \\
(40 \text { to } 50)\end{array}$ & $\begin{array}{c}80 \text { to } 87 \\
(50 \text { to } 54)\end{array}$ & $\begin{array}{c}87 \text { to } 93 \\
(54 \text { to } 58)\end{array}$ & $\begin{array}{c}93 \text { to } 100 \\
\text { (58 to 62) }\end{array}$ & $\begin{array}{c}100 \text { to } 105 \\
\text { (62 to 65) }\end{array}$ & $\begin{array}{r}>105 \\
(>65)\end{array}$ \\
\hline 0 & 0 & 0 & 0 & 0 & 0 & 0 & 0 & 0 \\
\hline $0-40$ & 83618 & 2074597 & 4239125 & 5713578 & 10681782 & 16837084 & 17312228 & 83667590 \\
\hline $40-50$ & 19836 & 1207299 & 1683603 & 2452934 & 4564131 & 8352367 & 9980718 & 55569146 \\
\hline $50-60$ & 38812 & 1623811 & 2870424 & 3430650 & 5828213 & 10634756 & 13065692 & 69066363 \\
\hline $60-70$ & 69593 & 1984298 & 6129301 & 3187143 & 7261609 & 13059804 & 15999266 & 75868759 \\
\hline $70-80$ & 83784 & 4060240 & 5123125 & 3923425 & 8192209 & 14998111 & 18355588 & 77752378 \\
\hline$>80$ & 159474 & 27282072 & 65008252 & 41713637 & 59863110 & $1.03 \mathrm{E}+08$ & $1.13 \mathrm{E}+08$ & $3.65 \mathrm{E}+08$ \\
\hline
\end{tabular}

** Gray area indicates traffic conditions that have enough number of observations during field study. 
Table 4: The percentage of vehicle trips within each volume-speed combinations compared to the daily traffic for all 454 station pairs in the Twin Cities freeway network during 44 days in 2008 when meteorological conditions are consistent with initial field study for at least 18 hours per day

\begin{tabular}{|c|r|r|r|r|r|r|r|r|}
\hline \multirow{2}{*}{ Volume } & \multicolumn{7}{|c|}{ Speed $\mathrm{km} / \mathrm{h}$ (miles/h) } \\
\cline { 2 - 9 } & $\begin{array}{c}<24 \\
(<15)\end{array}$ & $\begin{array}{c}24 \text { to } 64 \\
(15 \text { to } 40)\end{array}$ & $\begin{array}{c}64 \text { to } 80 \\
(40 \text { to } 50)\end{array}$ & $\begin{array}{c}80 \text { to } 87 \\
(50 \text { to } 54)\end{array}$ & $\begin{array}{c}87 \text { to } 93 \\
(54 \text { to } 58)\end{array}$ & $\begin{array}{c}93 \text { to } 100 \\
(58 \text { to } 62)\end{array}$ & $\begin{array}{c}100 \text { to } 105 \\
\text { (62 to 65) }\end{array}$ & $\begin{array}{c}>105 \\
(>65)\end{array}$ \\
\hline 0 & $0.0 \%$ & $0.0 \%$ & $0.0 \%$ & $0.0 \%$ & $0.0 \%$ & $0.0 \%$ & $0.0 \%$ & $0.0 \%$ \\
\hline $0-40$ & $0.0 \%$ & $0.2 \%$ & $0.3 \%$ & $0.4 \%$ & $0.8 \%$ & $1.2 \%$ & $1.3 \%$ & $6.1 \%$ \\
\hline $40-50$ & $0.0 \%$ & $0.1 \%$ & $0.1 \%$ & $0.2 \%$ & $0.3 \%$ & $0.6 \%$ & $0.7 \%$ & $4.1 \%$ \\
\hline $50-60$ & $0.0 \%$ & $0.1 \%$ & $0.2 \%$ & $0.3 \%$ & $0.4 \%$ & $0.8 \%$ & $1.0 \%$ & $5.1 \%$ \\
\hline $60-70$ & $0.0 \%$ & $0.1 \%$ & $0.5 \%$ & $0.2 \%$ & $0.5 \%$ & $1.0 \%$ & $1.2 \%$ & $5.6 \%$ \\
\hline $70-80$ & $0.0 \%$ & $0.3 \%$ & $0.4 \%$ & $0.3 \%$ & $0.6 \%$ & $1.1 \%$ & $1.3 \%$ & $5.7 \%$ \\
\hline$>80$ & $0.0 \%$ & $2.0 \%$ & $4.8 \%$ & $3.1 \%$ & $4.4 \%$ & $7.5 \%$ & $8.3 \%$ & $26.8 \%$ \\
\hline
\end{tabular}

** Gray area indicates traffic conditions that have enough number of observations during the field study. 
Table 5: Coefficients of estimated UFP PN concentration models for 32 bins of different particle size ranges and for the total number of all particles

\begin{tabular}{|c|c|c|c|c|c|}
\hline Bin no. & Size begin & Size end & Constant term & Avg. speed coeff. & Vol. sum Coeff. \\
\hline 1 & 5.6 & 6.04 & 4.1426 & -0.0076 & 0.0080 \\
\hline 2 & 6.04 & 6.98 & 3.9464 & -0.0050 & 0.0092 \\
\hline 3 & 6.98 & 8.06 & 4.0501 & -0.0043 & 0.0105 \\
\hline 4 & 8.06 & 9.31 & 4.2753 & -0.0061 & 0.0120 \\
\hline 5 & 9.31 & 10.8 & 4.4697 & -0.0082 & 0.0112 \\
\hline 6 & 10.8 & 12.4 & 4.2970 & -0.0089 & 0.0119 \\
\hline 7 & 12.4 & 14.3 & 4.0372 & -0.0078 & 0.0128 \\
\hline 8 & 14.3 & 16.5 & 4.0491 & -0.0084 & 0.0130 \\
\hline 9 & 16.5 & 19.1 & 3.9488 & -0.0081 & 0.0133 \\
\hline 10 & 19.1 & 22.1 & 3.9176 & -0.0099 & 0.0136 \\
\hline 11 & 22.1 & 25.5 & 3.8446 & -0.0090 & 0.0133 \\
\hline 12 & 25.5 & 29.4 & 3.8425 & -0.0078 & 0.0128 \\
\hline 13 & 29.4 & 34.0 & 3.9912 & -0.0088 & 0.0117 \\
\hline 14 & 34.0 & 39.2 & 3.9929 & -0.0086 & 0.0111 \\
\hline 15 & 39.2 & 45.3 & 3.9439 & -0.0077 & 0.0106 \\
\hline 16 & 45.3 & 52.3 & 3.9133 & -0.0075 & 0.0102 \\
\hline 17 & 52.3 & 60.4 & 3.9769 & -0.0084 & 0.0091 \\
\hline 18 & 60.4 & 69.8 & 3.8909 & -0.0069 & 0.0085 \\
\hline 19 & 69.8 & 80.6 & 3.8590 & -0.0061 & 0.0076 \\
\hline 20 & 80.6 & 93.1 & 3.7620 & -0.0049 & 0.0067 \\
\hline 21 & 93.1 & 107.5 & 3.6941 & -0.0044 & 0.0057 \\
\hline 22 & 107.5 & 124.1 & 3.6511 & -0.0045 & 0.0043 \\
\hline 23 & 124.1 & 143.3 & 3.5471 & -0.0044 & 0.0035 \\
\hline 24 & 143.3 & 165.5 & 3.3307 & -0.0034 & 0.0031 \\
\hline 25 & 165.5 & 191.1 & 3.2031 & -0.0040 & 0.0019 \\
\hline 26 & 191.1 & 220.7 & 3.0211 & -0.0068 & 0.0026 \\
\hline 27 & 220.7 & 254.8 & 2.8569 & -0.0143 & 0.0059 \\
\hline 28 & 254.8 & 294.3 & 2.6919 & -0.0187 & 0.0089 \\
\hline 29 & 294.3 & 339.8 & 2.6280 & -0.0152 & 0.0072 \\
\hline 30 & 339.8 & 392.4 & 2.7515 & -0.0131 & 0.0051 \\
\hline 31 & 392.4 & 453.2 & 2.7171 & -0.0112 & 0.0044 \\
\hline 32 & 453.2 & 523.3 & 2.6286 & -0.0100 & 0.0037 \\
\hline cumulative model & & & 5.441 & -0.006529 & 0.009739 \\
\hline
\end{tabular}




\section{FIGURES}

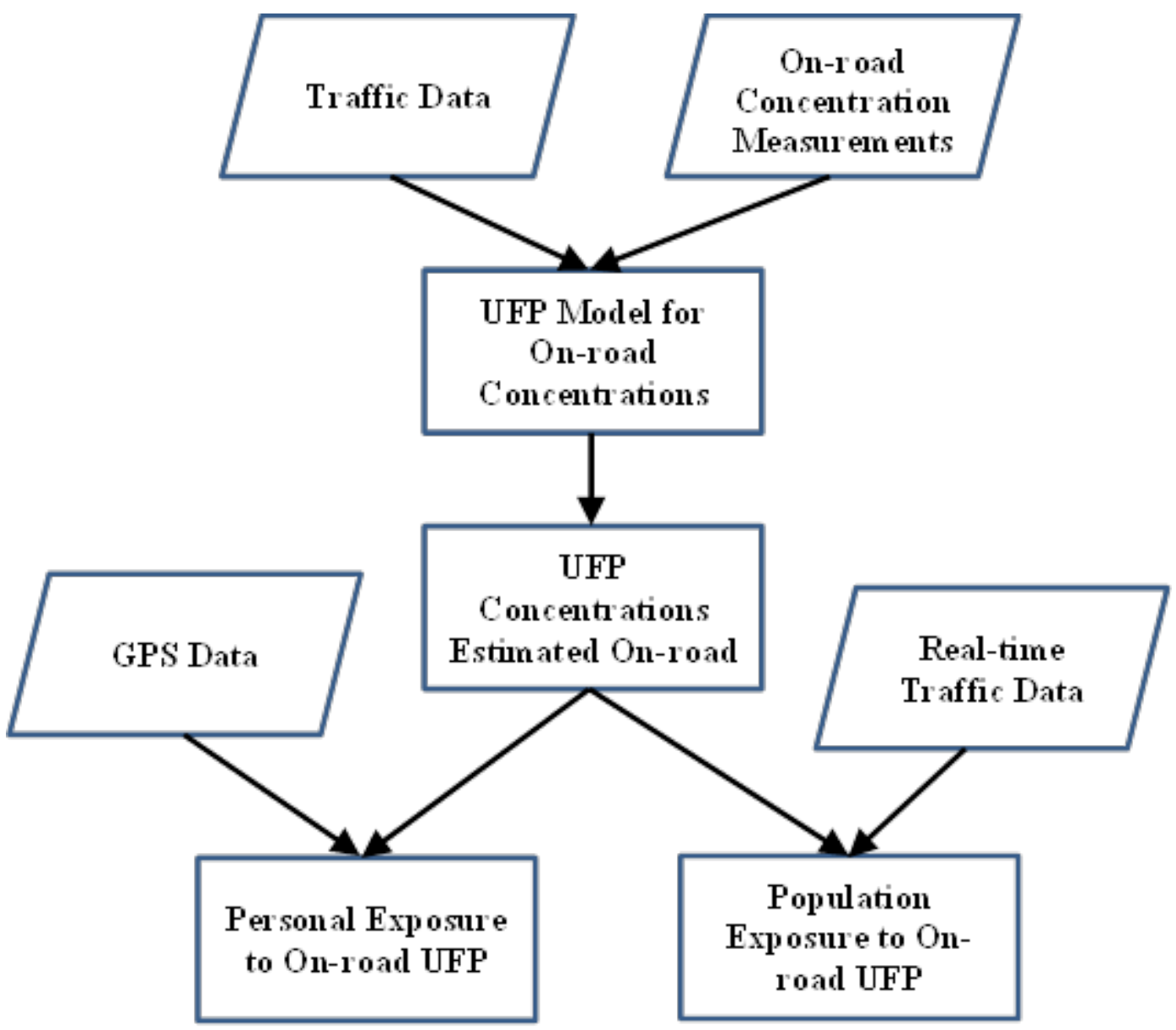

Figure 1: The flow chart of estimating on-route exposure to Ultra-Fine Particles of both individual traveler and general public at the Twin Cities, Minnesota 


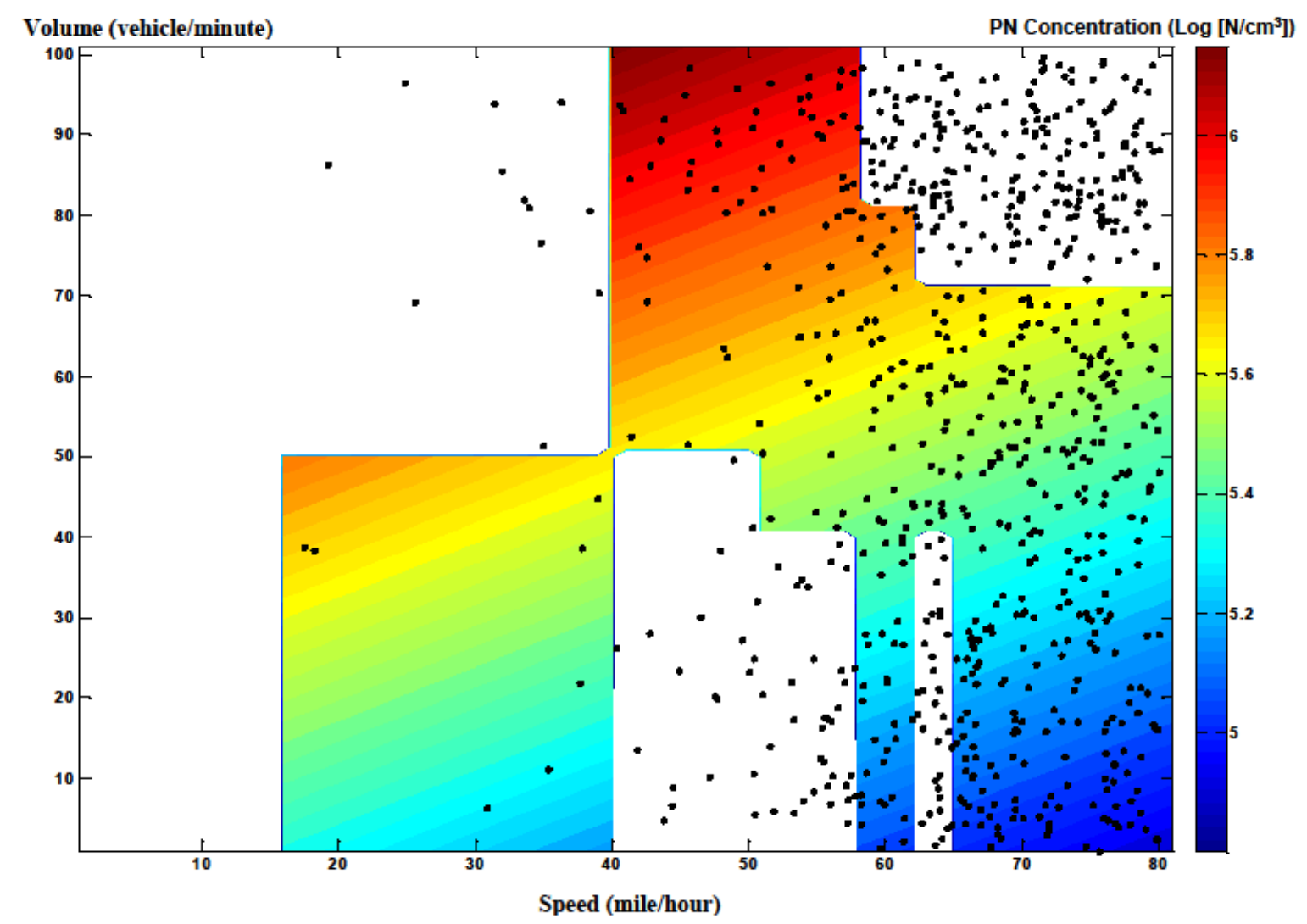

Figure 2: Prediction of total number of UFP given by different volume and speed combinations Black dots represent observed traffic conditions - specifically, the 1-minute observations at all 454 freeway loop-detector station pairs during the 44 modeled days in 2008. For visual display, each dot represents $0.1 \%$ of all 28,765,440 one-minute-station observations. 


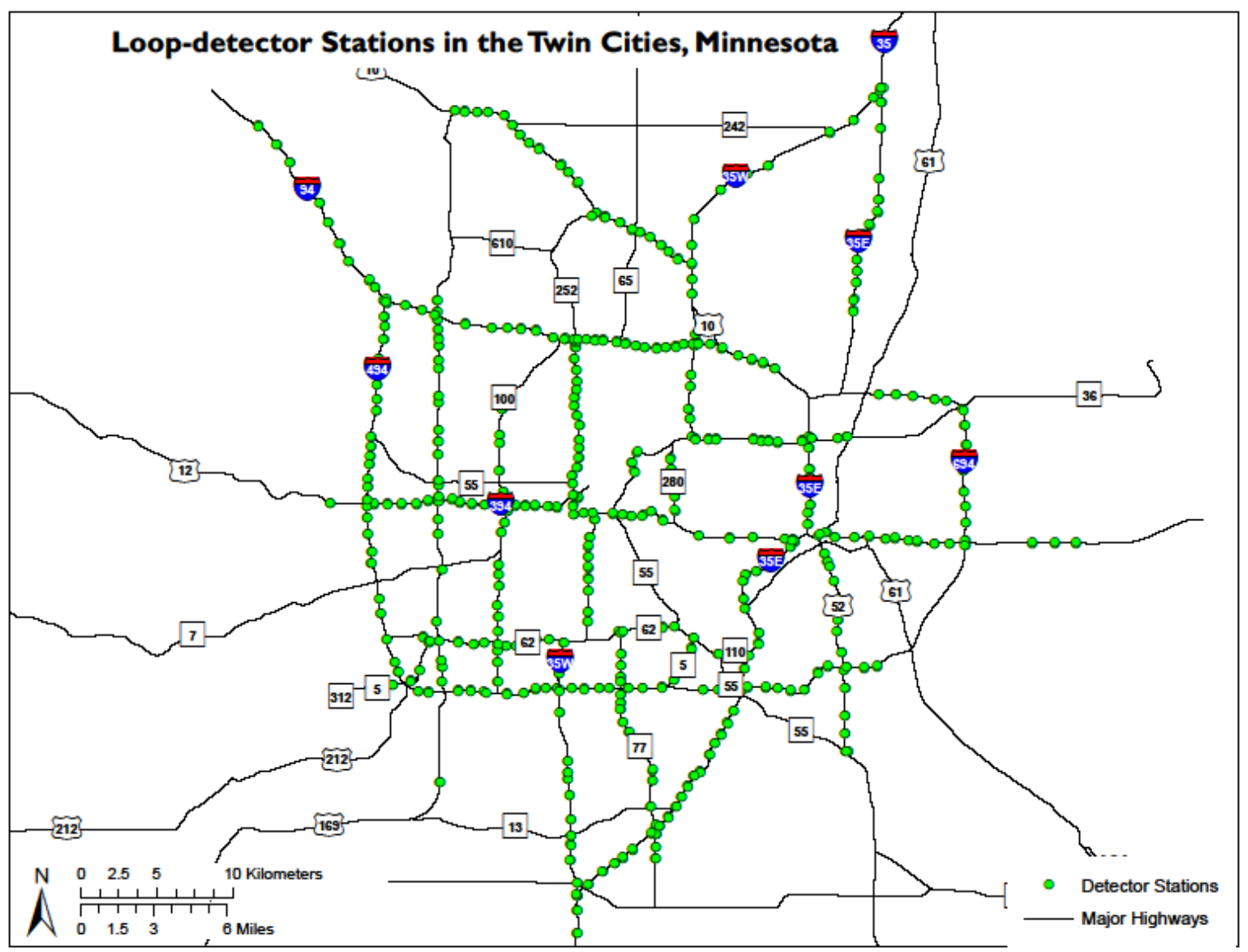

Figure 3: Map of the study area (Twin Cities, Minnesota) showing the 454 paired bidirectional traffic-detector stations employed in this study. 


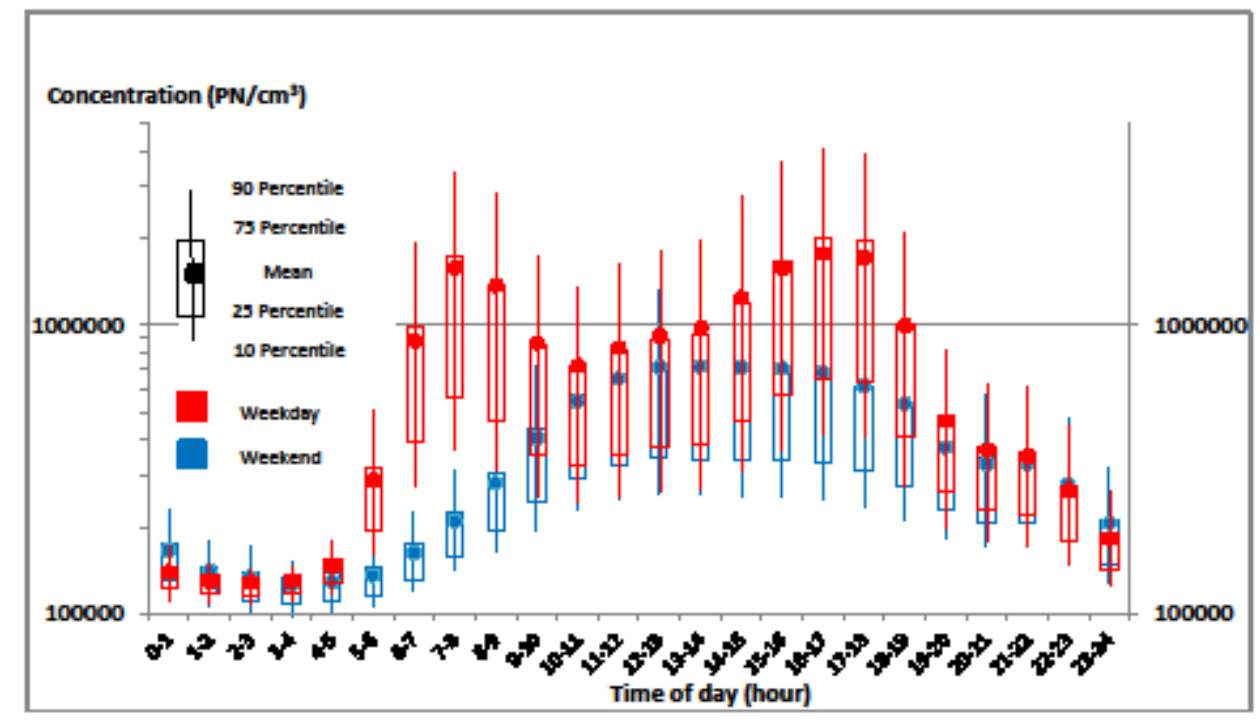

Figure 4: Distribution of total on-freeway UFP concentration by hour-of day 


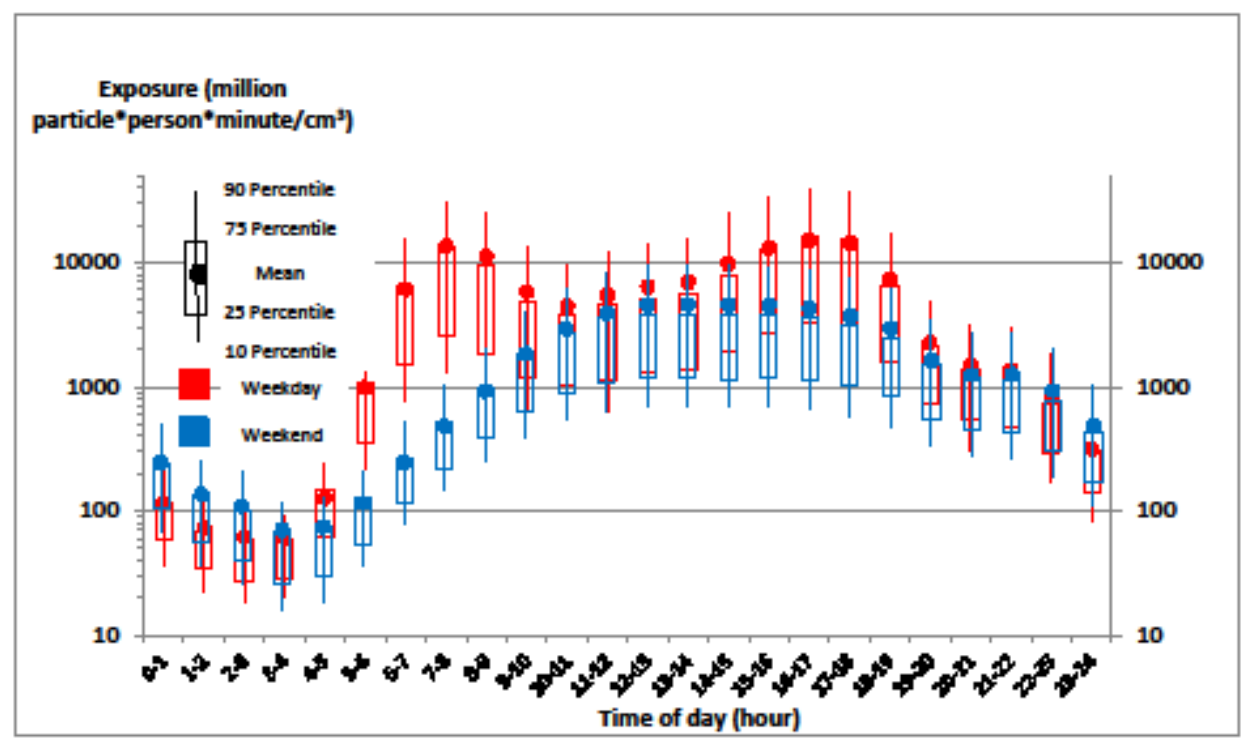

Figure 5: Distribution of average hourly on-freeway UFP Exposure 


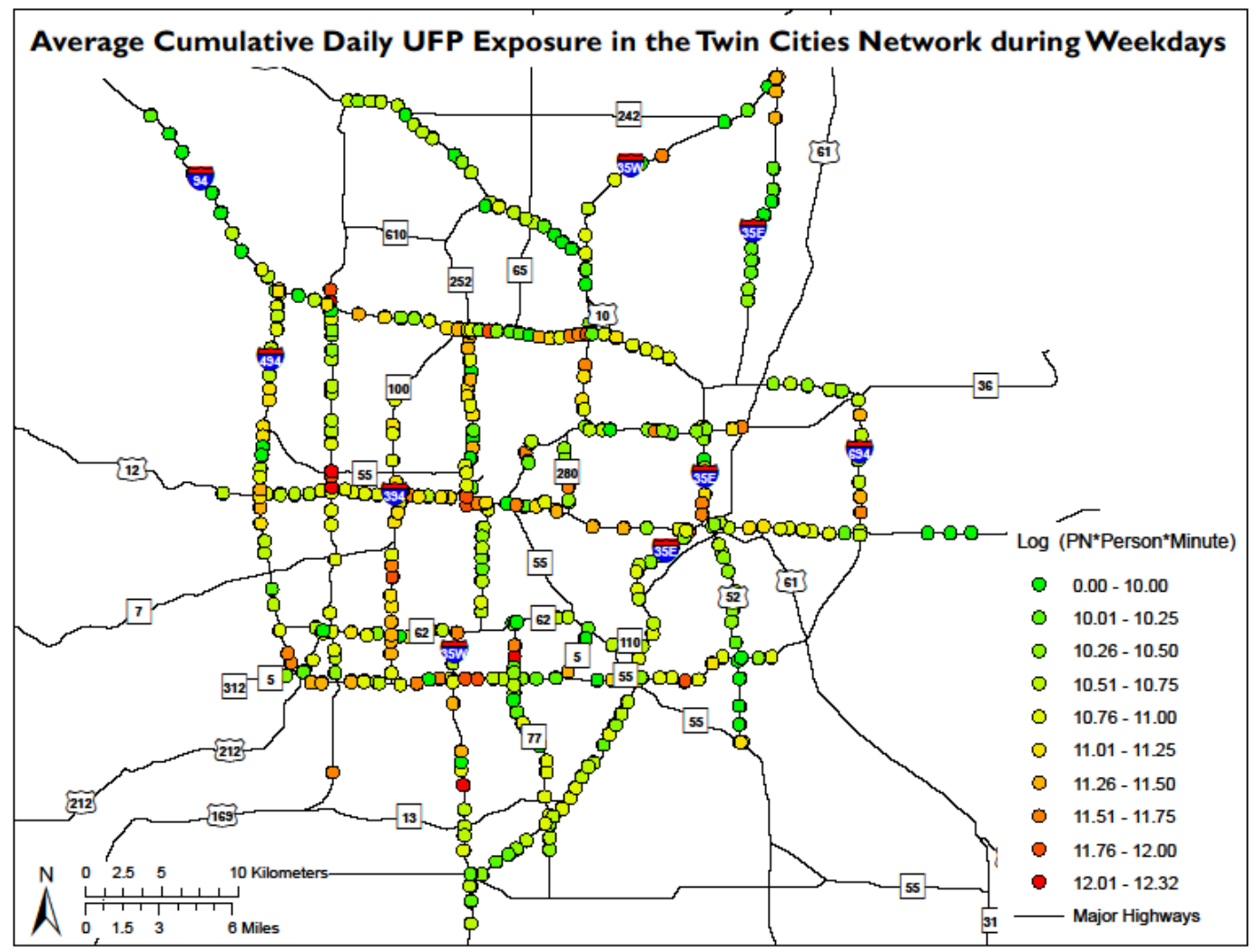

Figure 6: Cumulative Daily UFP Exposure in the Twin Cities Network on Weekdays 


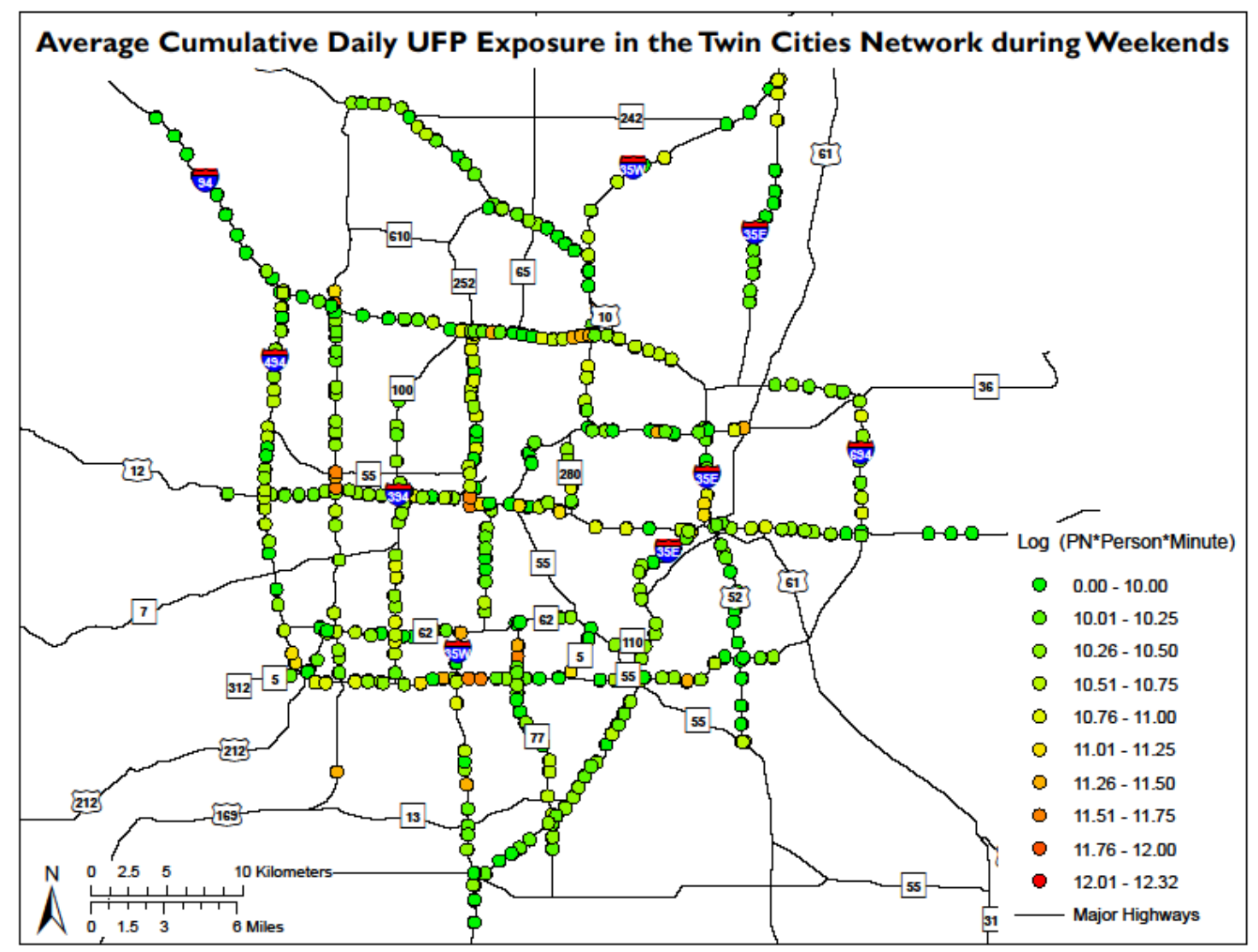

Figure 6: Cumulative Daily UFP Exposure in the Twin Cities Network on Weekends 


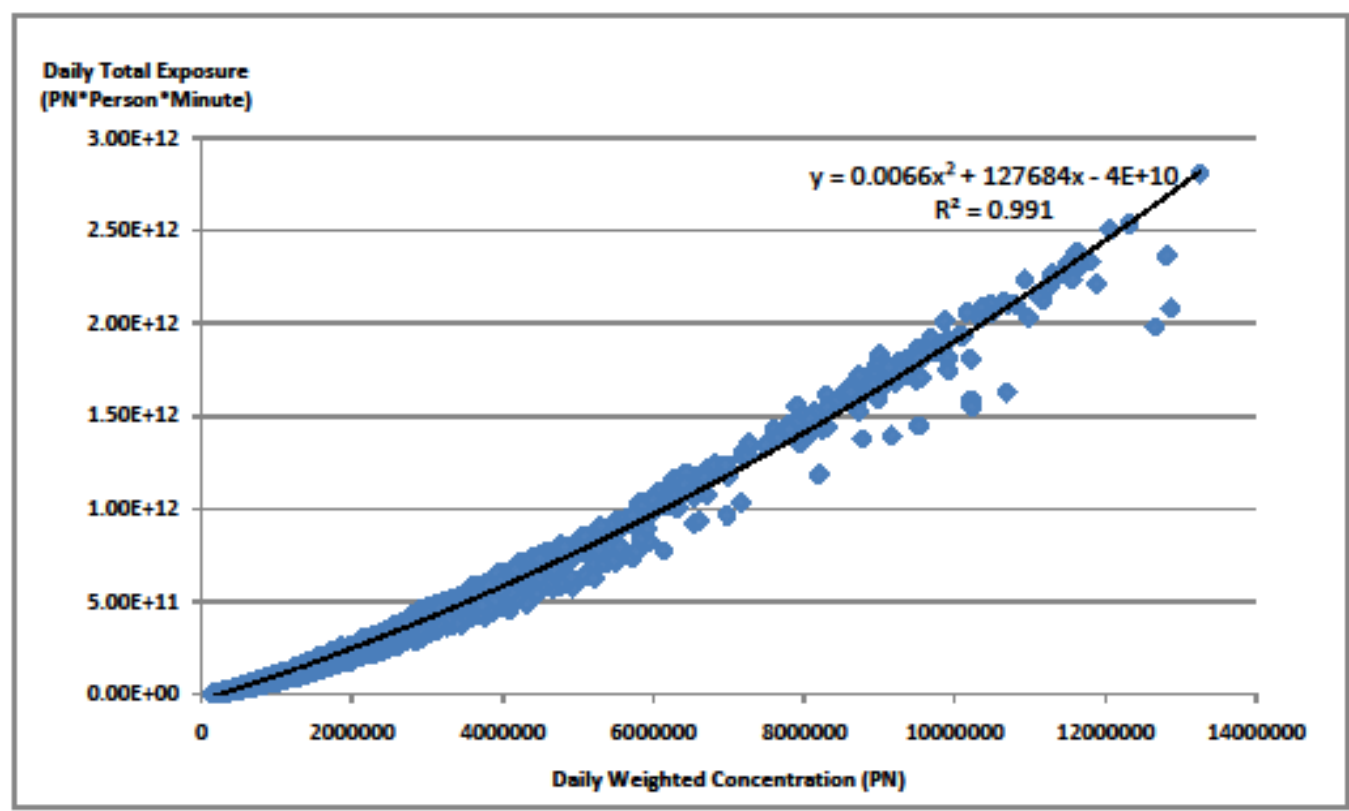

Figure 7a: Daily exposure vs. Person-Weighted Average Concentration 


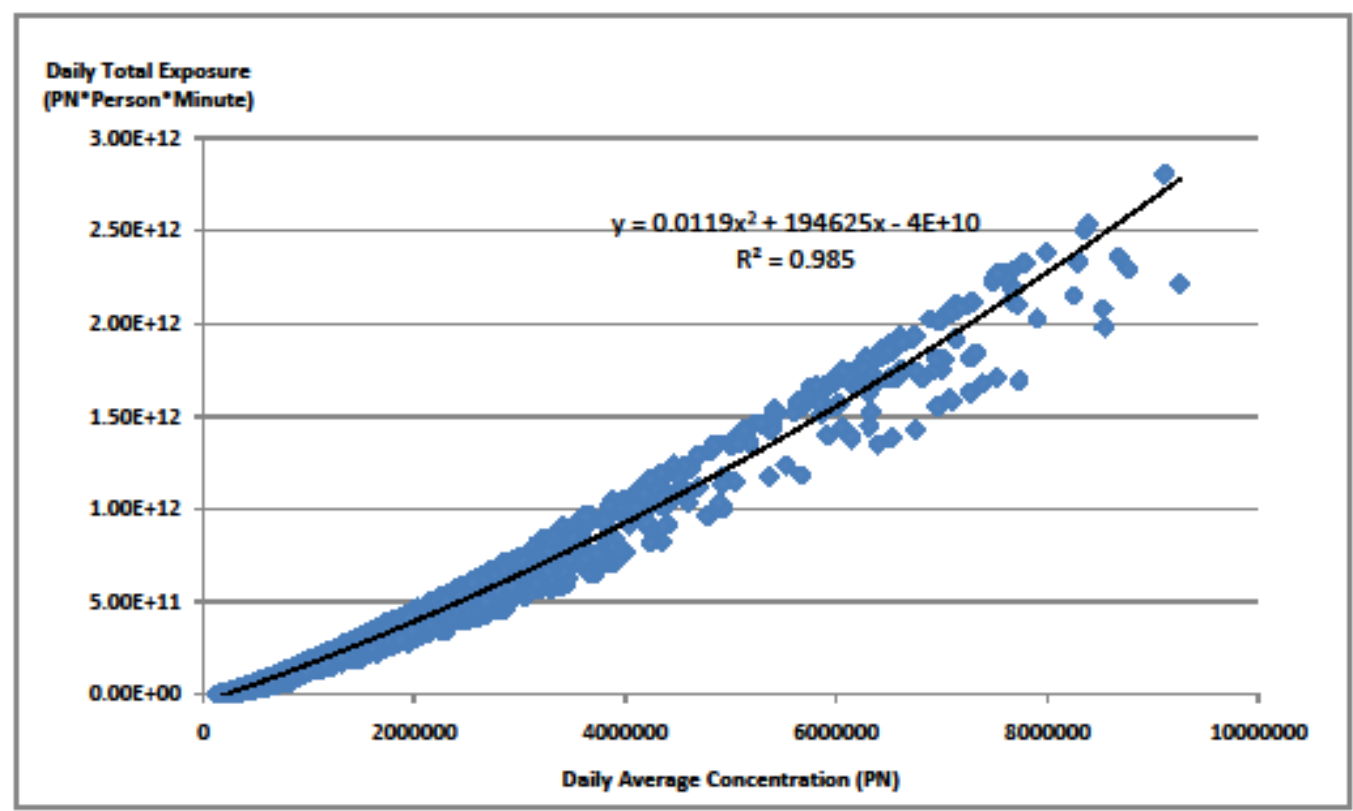

Figure 7b: Daily exposure vs. Simple Daily Average Concentration 

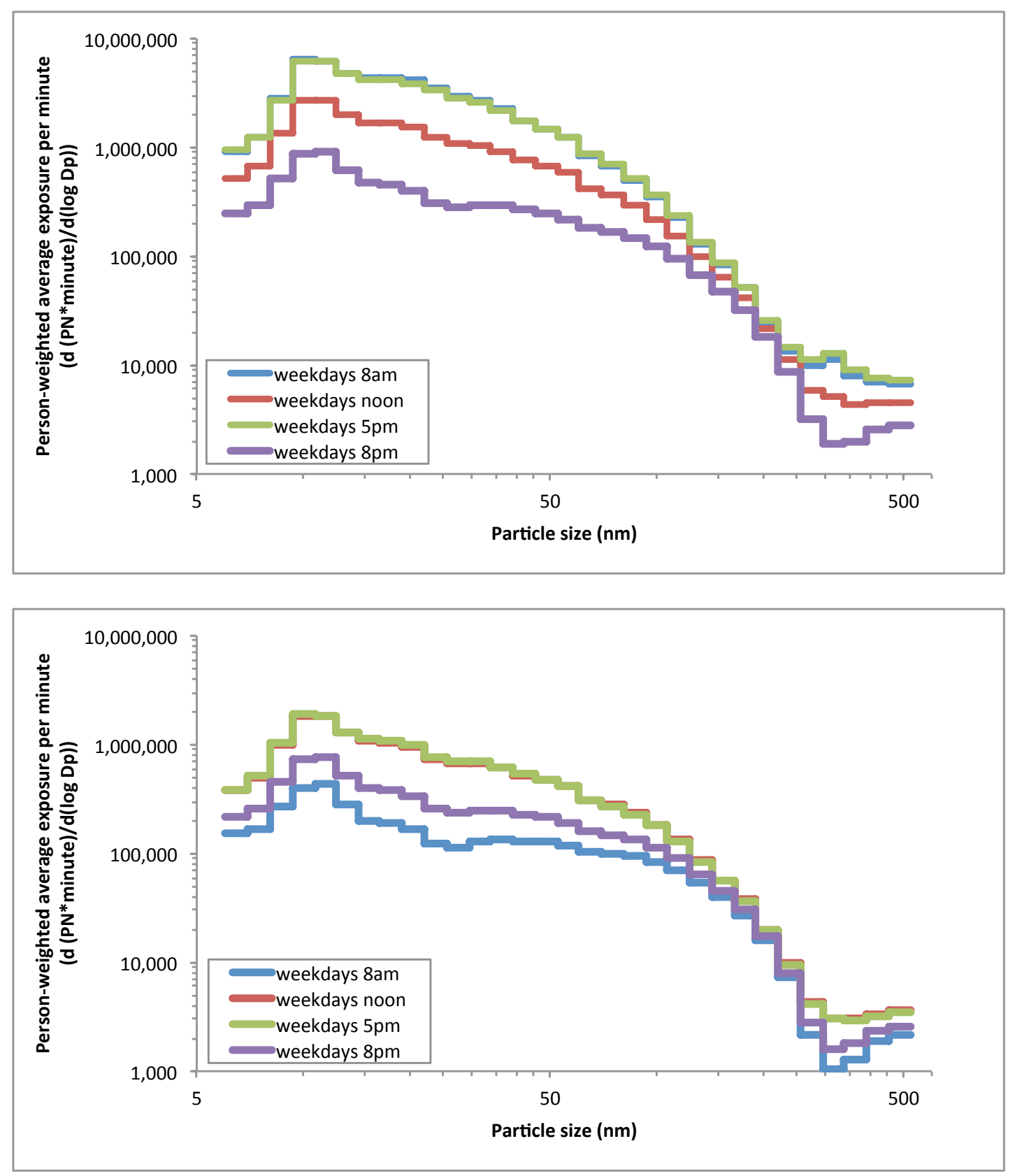

Figure 8: Exposure to UFP by size range during weekdays (upper) and weekends (lower). Note the log scale. On weekdays, lines displayed are similar for 8 am and 5pm. On weekends, lines displayed are similar for noon and $5 \mathrm{pm}$. 


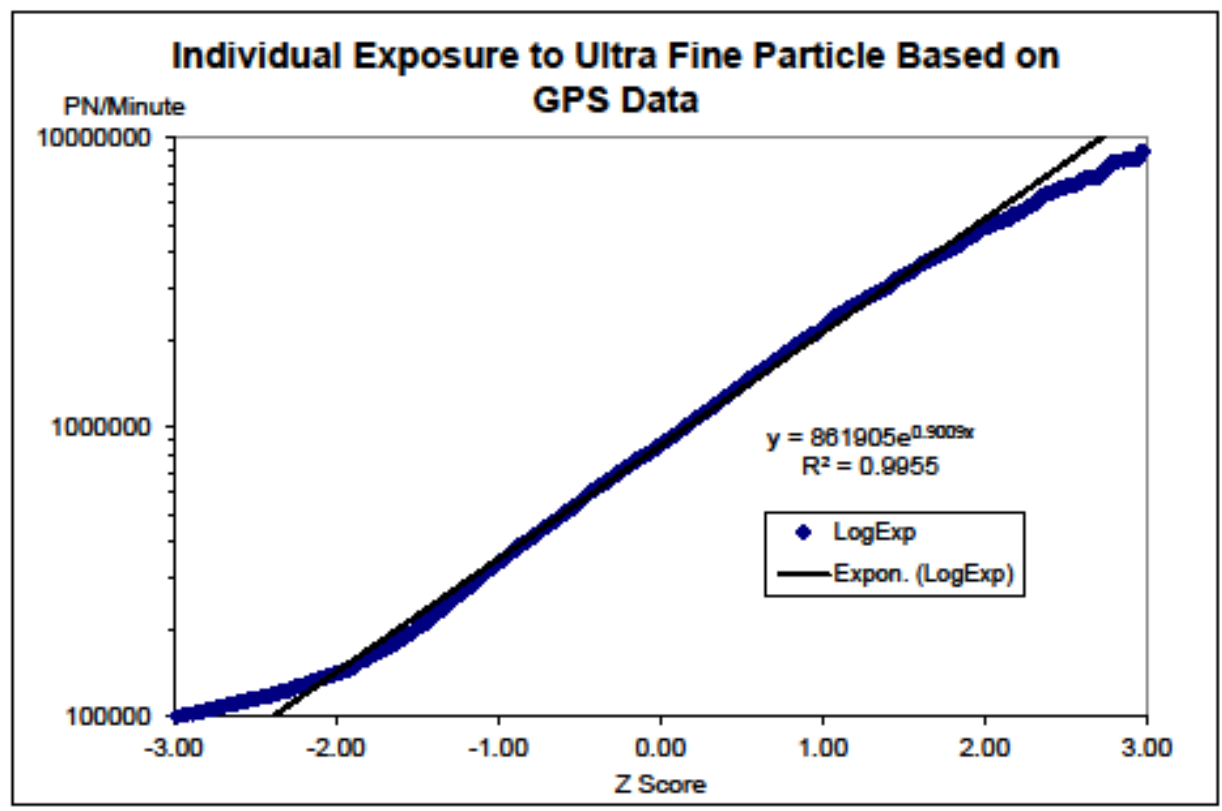

Figure 9: Individual exposure to UFP based on GPS data, sorted from low to high 